Journal of Advanced Research in Fluid Mechanics and Thermal Sciences

Journal homepage: www.akademiabaru.com/arfmts.html ISSN: 2289-7879

\title{
Study on the Application of Particle Image Velocimetry with Resin and Rhodamine B as Alternative Seeding Particles in Pico Hydro Cross Flow Hydro Turbine
}

\author{
Warjito ${ }^{1}$, Elang Pramudya Wijaya ${ }^{1,{ }^{*}}$, Budiarso $^{1}$, Sanjaya Baroar Sakti Nasution ${ }^{1}$, Agil Fadhel \\ Kurnianto ${ }^{1}$
}

1 Mechanical Engineering Department, Faculty of Engineering, Universitas Indonesia, Depok, West Java, 16424, Indonesia

\begin{tabular}{ll} 
ARTICLE INFO & ABSTRACT \\
\hline $\begin{array}{l}\text { Article history: } \\
\text { Received } 11 \text { April } 2021\end{array}$ & $\begin{array}{l}\text { One of the solutions to overcome the lack of electricity problem in rural area is } \\
\text { Received in revised form } 10 \text { July } 2021\end{array}$ \\
$\begin{array}{l}\text { Accepted } 16 \text { July } 2021 \\
\text { Available online } 26 \text { July } 2021\end{array}$ & $\begin{array}{l}\text { measurement is one of the methods used to visualize the fluid flow phenomena inside } \\
\text { the turbine. Expensive price of seeding particle leads to find the solution for this PIV } \\
\text { method. The objective of this study is to use a cheap seeding particle from cheaper } \\
\text { materials, mainly resin and rhodamine B. Besides that, in this study, PIV measurement } \\
\text { is compared to 2D computational fluid dynamics (CFD) with multiphase volume of fluid } \\
\text { model. From the results, several phenomena can be observed at both of the methods } \\
\text { (PIV and CFD) such as separation in the blade tip. Therefore, this study showed that an } \\
\text { inexpensive material resin and rhodamine B as a seeding particle has a potential and } \\
\text { Crossflow; banki turbine; pico-hydro; }\end{array}$ \\
$\begin{array}{l}\text { Particle Image Velocimetry } \\
\text { ability to represent flow inside pico-hydro cross-flow turbine. }\end{array}$
\end{tabular}

\section{Introduction}

One of the solutions to overcome the lack of electricity problem in rural area is Pico-hydropower. Pico hydropower systems are capable to producing up to $5 \mathrm{~kW}$ of electricity. The output of pico hydropower depends on the head and flow rate of the stream, which the stream need to fulfil the turbine characteristic to ensure the turbine to generate enough power as required [1]. The capacity of micro and pico-hydro have significant contribution in electrification program and off-grid settlements [1].Compared to the large, medium, and micro scale, pico- hydro turbine requires low cost and has several advantages such as eco-friendly, easy to build, high efficiency, and mobile [2], [3]. Based on the previous study by [4] pico-hydro cross-flow turbine is recommended for an independent power plant in rural area. Moreover, cross-flow type pico-hydro turbine can be used in various head conditions and economically made with simple design [5].

\footnotetext{
* Corresponding author.

E-mail address: elangpw@outlook.com

https://doi.org/10.37934/arfmts.85.1.111
} 
In improving cross-flow turbine performance, understanding fluid phenomena is needed. Particle image velocimetry (PIV) measurement is one of the methods used to visualize the fluid flow phenomena inside the turbine. PIV processing can be defined as comparing the seeding particles from two successive images of an illuminated plane in the flow [6]. Nishi et al., used PIV to investigate internal flow structure of small axial hydro turbine [7]. Duquesne et al., investigated flow separation in a diffuser of bulb turbine using PIV [8]. Iliescu et al., measured velocity profiles in side draft-tube using PIV [9]. Pedersen et al., [10] investigated an impeller with fluorescent polymer particles in PIV measurements with $1.5 \mathrm{~g} / \mathrm{cm}^{3}$ density [10]. Dupont et al., [11] performed PIV measurements on a shockwave induced separation on a Mach 2.3 wind tunnel. Furthermore, a PIV measurement in crossflow turbines require a high amount of seeding particle. Due to expensive price and the highly needs of the seeding particle in this study requires an alternative to substitute the seeding particle itself. Development on an alternative seeding particle required to press the budget and make this study efficient to visualizing cross-flow turbine by a cheaper material. One option is to use mixture of rhodamine $B$ and resin as an alternative seeding particle in PIV measurement. Therefore, the purpose of this study is to analyze the application of rhodamine $B$ and resin as an alternative material of seeding particle in crossflow turbine PIV measurement.

\section{Methodology}

\subsection{Seeding Particle Alternative}

A good seeding particle is a seeding particle that has non-toxic, non-corrosive, non-abrasive, non volatile, and chemically inert properties [12]. Several types of material seeding particles can be described in the following Table 1.

Table 1

Seeding particle in a fluid flow [12]

\begin{tabular}{|c|c|c|c|c|c|c|}
\hline \multirow[t]{3}{*}{ Material } & \multirow{2}{*}{\multicolumn{2}{|c|}{$d_{p}(\mu m)$ Laser }} & \multirow{3}{*}{$\begin{array}{l}\text { CW power } \\
\text { or } \\
\text { energy, time }\end{array}$} & \multicolumn{3}{|c|}{ Light sheetReference } \\
\hline & & & & \multirow{2}{*}{$\begin{array}{l}w \\
e(\mathrm{~mm})\end{array}$} & \multirow{2}{*}{\multicolumn{2}{|c|}{$\begin{array}{l}t \\
(\mathrm{~mm})\end{array}$}} \\
\hline & & & & & & \\
\hline$\overline{\mathrm{TiO}_{2}}$ & 3 & $\mathrm{Nd}: Y A G$ & & & & [13] \\
\hline $\mathrm{Al}_{2} \mathrm{O}_{3}$ & 9.5 & Ruby & $2 \mathrm{~J}, 30 \mathrm{~ns}$ & 100 & 0.8 & {$[14]$} \\
\hline $\begin{array}{l}\text { Conifer pollen } \\
\left(=1000 \mathrm{~kg} \mathrm{~m}^{-3}\right)\end{array}$ & $50-60$ & Arion & $1-2 W$ & & & [14-16] \\
\hline $\begin{array}{l}\text { Polymer } \\
\left(=1030 \mathrm{~kg} \mathrm{~m}^{-3}\right)\end{array}$ & 30 & Arion & $0.5-5 \mathrm{~W}$ & & 0.5 & {$[15],[16]$} \\
\hline $\begin{array}{l}\text { Phosphorescent } \\
\text { polymer }\end{array}$ & t80 & Arion & $5 \mathrm{~W}$ & & 1 & [17] \\
\hline Fluorescent & 50 & $\mathrm{Nd}: Y A G$ & & & & [18] \\
\hline & 20 & Cu vapou & r45 W & & 1 & [19] \\
\hline Polystyrene & 500 & & & & & [20] \\
\hline$\left(=1050 \mathrm{~kg} \mathrm{~m}^{-3}\right)$ & 15 & Ruby & $25 \mathrm{~mJ}, 20 \mathrm{~ns}$ & & & {$[21]$} \\
\hline $\begin{array}{l}\text { Thermoplastic } \\
\left(=1020 \mathrm{~kg} \mathrm{~m}^{-3}\right)\end{array}$ & 6 & Nd:YAG & & 50 & 2 & {$[22]$} \\
\hline Reflective & 60 & Arion & $18 \mathrm{~W}$ & & & {$[23]$} \\
\hline$\left(=1010 \mathrm{~kg} \mathrm{~m}^{-3}\right)$ & 30 & Arion & $12-18 \mathrm{~W}$ & 200 & & {$[24]$} \\
\hline Metallic coated & & Arion & $2 W$ & & 2 & {$[25]$} \\
\hline & 14 & Arion & & & 1 & {$[26]$} \\
\hline $\begin{array}{l}\text { Microspheres } \\
\left(=700 \mathrm{~kg} \mathrm{~m}^{-3}\right)\end{array}$ & $<30$ & Arion & & & & {$[27]$} \\
\hline $\mathrm{H}_{2}$ bubbles & & Arion & $1 \mathrm{~W}$ & & 0.3 & {$[28]$} \\
\hline
\end{tabular}


Seeding particle used refers to the type of laser, laser power output, and also the thickness of the light sheet in the experiment. However, the thickness of the light sheet can be ignored. In addition, the properties of the seeding particle must be adjusted to the working fluid. The particles chosen in this experiment have a density value close to the working fluid, which is water. Furthermore, the particles can move to follow the flow of water. The time interval of particles to follow the flow of working fluid is made by a condition of whether or not the seeding particle is. The smaller the time interval for responding, the greater the ability of particles to follow the direction of flow [29].

Furthermore, several materials can be used for seeding, according to [28], hydrogen bubbles can be used too for seeding. However, the buoyancy of the hydrogen bubbles make it float. Moreover, spherical glass can be used for seeding too.

The objective of this study is to use a cheap seeding particle from cheaper materials, mainly resin and rhodamine B. The chosen materials rhodamine B which found in many shops, commonly used as tracer dyes. The making of this seeding particle consists of several steps, first of all, Rhodamine B with $0.1 \%$ of the overall weight mixed with commercial grade liquid polyresin which regularly used in fiberglass or carbon fiber making. The $0.1 \%$ of concentration selected to minimize the amount of dye. The solid block of resin and rhodamine B then grinded to obtain the powder, then we used 200 mesh of sieve to get the smaller particles of $65 \mu \mathrm{m}$ or finer.

\subsection{PIV Experiment Set Up}

In this experiment, we used the Fluid Mechanics Laboratory facility, namely Dantec PIV System and Computer (Figure 1). Dantec PIV System consist of four major parts, first is the double cavity $\mathrm{Nd}$ :YAG laser itself with pulse energy up to $800 \mathrm{~mJ}$, the laser power supply, the computer itself which running with dantec dynamic software and the CCD camera with $532 \mathrm{~nm}$ filter, to capture the emissions from the seeding particles. The area captured has $1600 \times 1200$ pixel of resolution, with 20 $\mathrm{cm} \times 20 \mathrm{~cm}$ of area captured. The camera aperture was $f / 20$ with $532 \mathrm{~nm}$ filter which depends on the lightning in the laboratory.
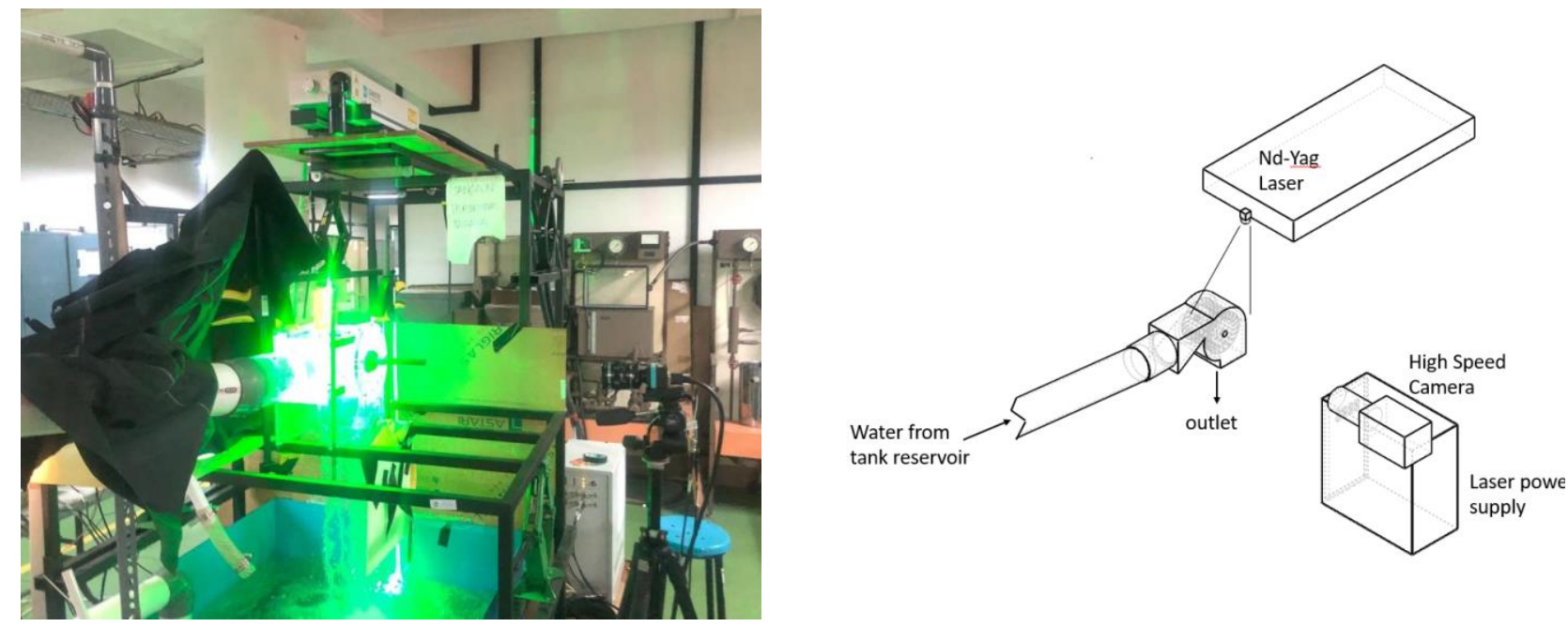

Fig. 1. PIV setup experiment

Then, the crossflow turbine was placed in the middle of the system with the laser was placed above the interrogation area. This crossflow turbine test model has previously been made using acrylic glass. In addition, a black cloth is given behind the model to reduce noise in the image results. 
The model itself used from the geometry of previous study by [30]. The geometry of this crossflow turbine shown in Table 2 below (See Figure 2).

Table 2

Cross-flow turbine geometry

\begin{tabular}{lll}
\hline Description & Value & Unit \\
\hline Number of blades $(Z)$ & 20 & blades \\
Blade length $(L)$ & 142 & $\mathrm{~mm}$ \\
Inner diameter $\left(D_{\text {in }}\right)$ & 117 & $\mathrm{~mm}$ \\
Outer diameter $\left(D_{\text {out }}\right)$ & 180 & $\mathrm{~mm}$ \\
Blade's angle of attack $(\alpha)$ & 22 & $\circ$ \\
Water tangential velocity $(V t)$ & 1.1 & $\mathrm{~m} / \mathrm{s}$ \\
Inlet Velocity $(V)$ & 0.01167 & $\mathrm{~m} / \mathrm{s}$ \\
$B_{1}$ & 42 & $\circ$ \\
Tangential velocity $(U)$ & 1.1 & $\mathrm{~m} / \mathrm{s}$ \\
\hline
\end{tabular}

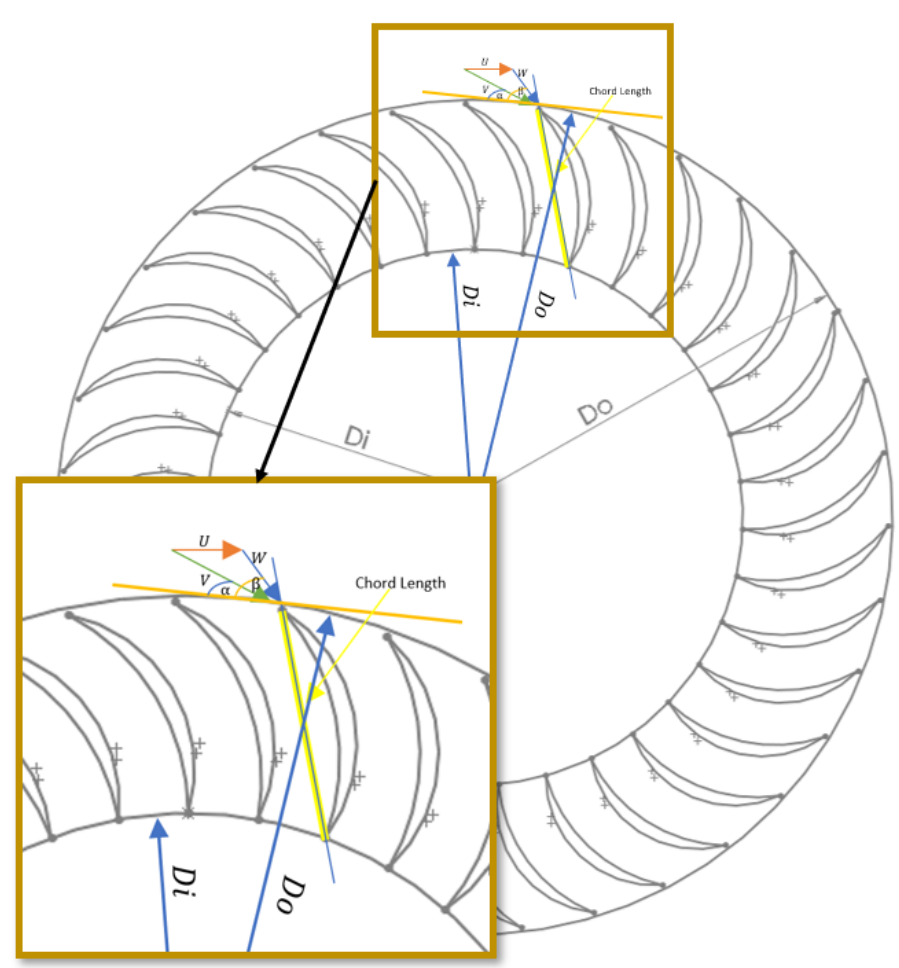

Fig. 2. 2D model of the blade [2]

\subsection{Calibration Method}

This experiment's flow velocity calibration method was done twice: software calibration and the device setup calibration. This study used PIV Lab software to determine the reference distance per pixel in the photos captured. A ruler shows a second base reference stuck at the experiment model. After that, this study determines the time-step related to camera settings and specifications. The resulting length per pixel in the camera captured images shows $1 p x=0.00017 \mathrm{~m}$. 


\subsection{Simulation Setup}

ANSYS TM Fluent $18.1^{\circledR}$ academic version is used in this study to fulfil the computational data. This simulation performed in 2D domain with multiphase volume of fluid model. Implicit volume fraction and body force was chosen based on the real conditions with two phase, air and water. Furthermore, multiphase volume of fluid (VoF) combined with implicit volume fraction and body force was used, this is the same as the simulation set up in a previous cross-flow turbine study $[3,16]$. The $k-\varepsilon$ RNG viscous model also used because based on assessment this model is optimally for this case $[4,17]$. The following is Figure 3 about the boundary conditions and mesh used in this study.

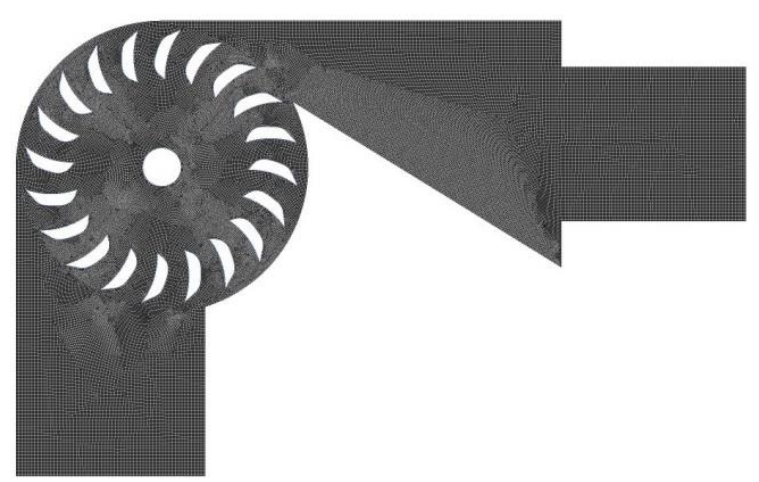

(a)

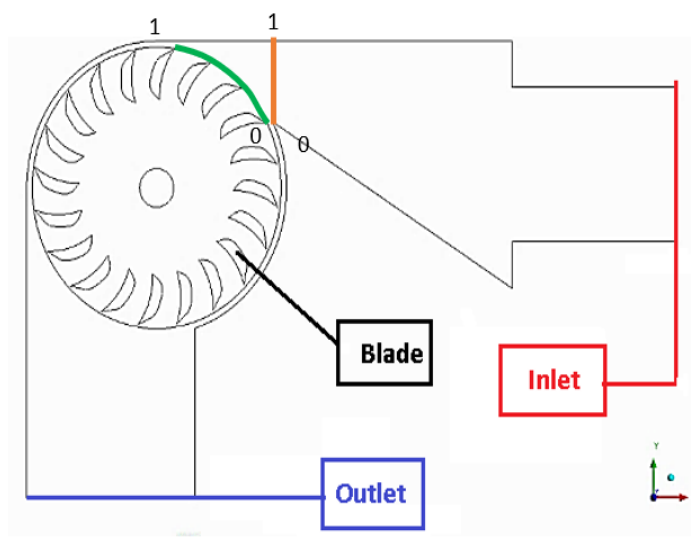

(b)

Fig. 3. (a) Meshing and (b) Boundary condition

This study's boundary conditions used a pressure inlet valued at $9810 \mathrm{~Pa}$ in the inlet and $0 \mathrm{~Pa}$ in the outlet. 0 value of outlet pressure means equal to atmospheric pressure on the system. The rpm value was 0 , causing the turbine rotation didn't rotate. The purpose of using this setup since the experimental setup didn't turn as well.

\subsection{Mesh Independency}

To get the appropriate number of elements, a comparison of the independence test mesh was performed on the geometry by conducting several simulations. After this independence test mesh process, the number of elements was obtained. Some variations in the mesh number of elements valued from 18996, 32484, 64450, and 128848. The number of mesh elements was chosen to get the exact ratio for choosing the appropriate mesh. Grid Convergence Index (GCl) by Richardson extrapolation was used to calculate error in this simulation, which was calculated based on the equation below [32].

$G C I_{a b}=H\left|\frac{1}{\tau_{a}} \frac{\tau_{b}-\tau_{a}}{r_{a b}{ }^{K}-1}\right| \times 100 \%$

where, $\mathrm{H}$ defines the safety factor, and $r$ is the grid refinement ratio which shown in the equation below

$r_{a b}=\left(\frac{M_{a}}{M_{b}}\right)^{0.5}$ 
Furthermore, after choosing the exact value of mesh, 128848 elements chosen for this simulation setup. The torque generated from mesh independency test was $2.69838 \mathrm{Nm}$, since the torque generated from the Richardson extrapolation method was $2.701 \mathrm{Nm}$. From the calculated torque, $\mathrm{GCl}$ value was $0.015628 \%$. The conclusion, mesh with 128848 elements was good enough to this simulation setup. Table 3 shows the mesh independency result.

Table 3

Grid convergence index

\begin{tabular}{lllll}
\hline Normalized grid spacing & Grid & Normalized grid spacing & Torque & $\mathrm{GCl}(\%)$ \\
\hline 2.60 & 18996 & 2 & 225.6876 & 0.062162 \\
1.99 & 32484 & 5 & 255.0654 & 0.085515 \\
1.41 & 64450 & 7 & 266.5926 & 0.027838 \\
1.00 & 128848 & 14 & 269.838 & 0.015628 \\
\hline
\end{tabular}

Then, the simulation setup process started. At this stage, the boundary conditions are set according to the actual conditions. In this stage, the flow rate, inlet velocity, multiphase and so on will be determined. Flow patterns, torque, pressure and others can be seen on the CFD-Post menu.

\section{Results}

\subsection{Static Seeding Particle and Calibration}

Compared to alternative seeding particle which made by [33], with the same laser specification used (wavelength $864 \mathrm{~nm}$, and 532nm lens which showed in Figure 3. Relatively, the diameter of seeding particles in this experiment varied from 10-75 microns. Fluorescent particles with 75 micron in diameter fulfilled Hiu Hu recommendation in his lecturer with 10-100 micron in diameter and 1.03$1.05 \mathrm{~kg} / \mathrm{cm}^{3}$ in density value [34]. The laser light reflection can be seen clearly in this experiment. On the other hand, unequal particle diameter causes sedimentation at the bottom of the channel. Figure 4 below is a comparison of seeding particle between Pedocci et al., experiment and the experiment in this study.

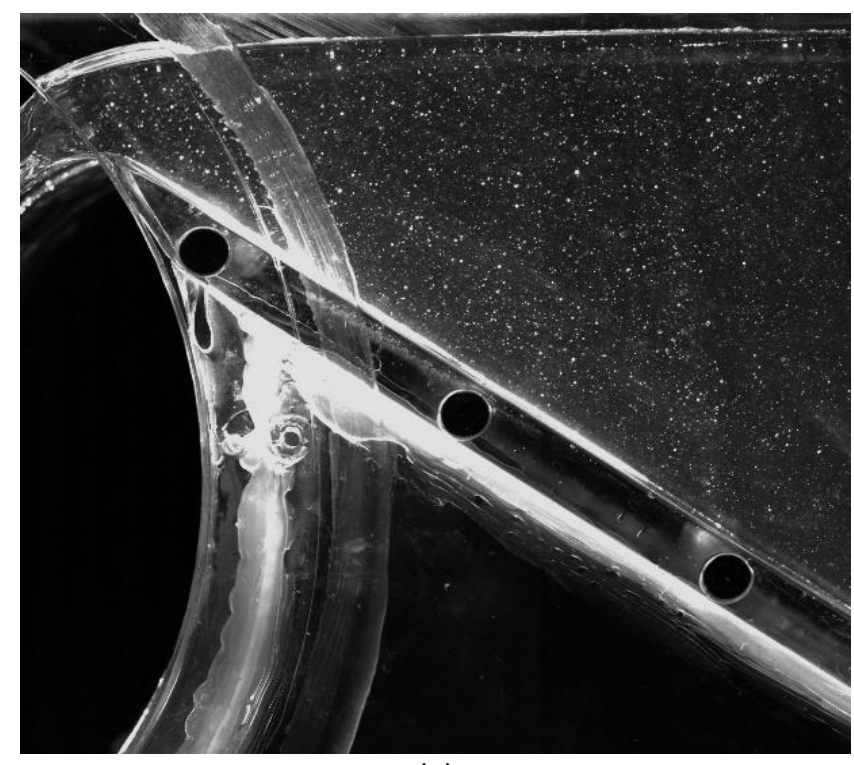

(a)

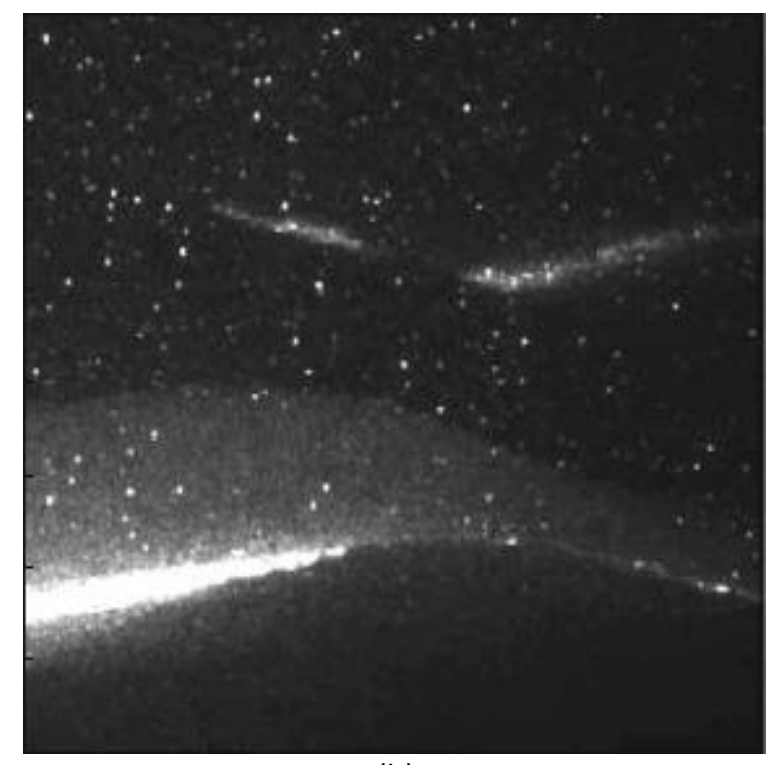

(b)

Fig. 4. Static seeding particle (a)This study (b) [33] 
The result of calibration in this study is compared to the flow-meter calculation result. Furthermore, the comparison of Flow-meter results and PIV result can be seen in Table 4 below. Uncertainty value is 0.011576 , this value is below $5 \%$ which means this experiment satisfy the rules for uncertainty method [35].

Table 4

Grid convergence index

\begin{tabular}{llll}
\hline No & $\begin{array}{l}\text { Flowmeter } \\
\text { Mean }(\mathrm{m} / \mathrm{s})\end{array}$ & $\begin{array}{l}\text { Piv } \\
\text { Mean }(\mathrm{m} / \mathrm{s})\end{array}$ & Uncertanity \\
\hline 1 & 1.439 & 1.147 & 0.0115768131 \\
\hline
\end{tabular}

\subsection{Velocity Distribution}

Seeding particle testing in this study was conducted by comparing the results of PIV and CFD. In this study, water magnitude velocity measurements were made at two positions; at the end of the nozzle and on stage in front of the blade (see Figure 3(b)). Figure 5 below is a velocity profile at the end of the nozzle (orange line in Figure $3(b)$ ).

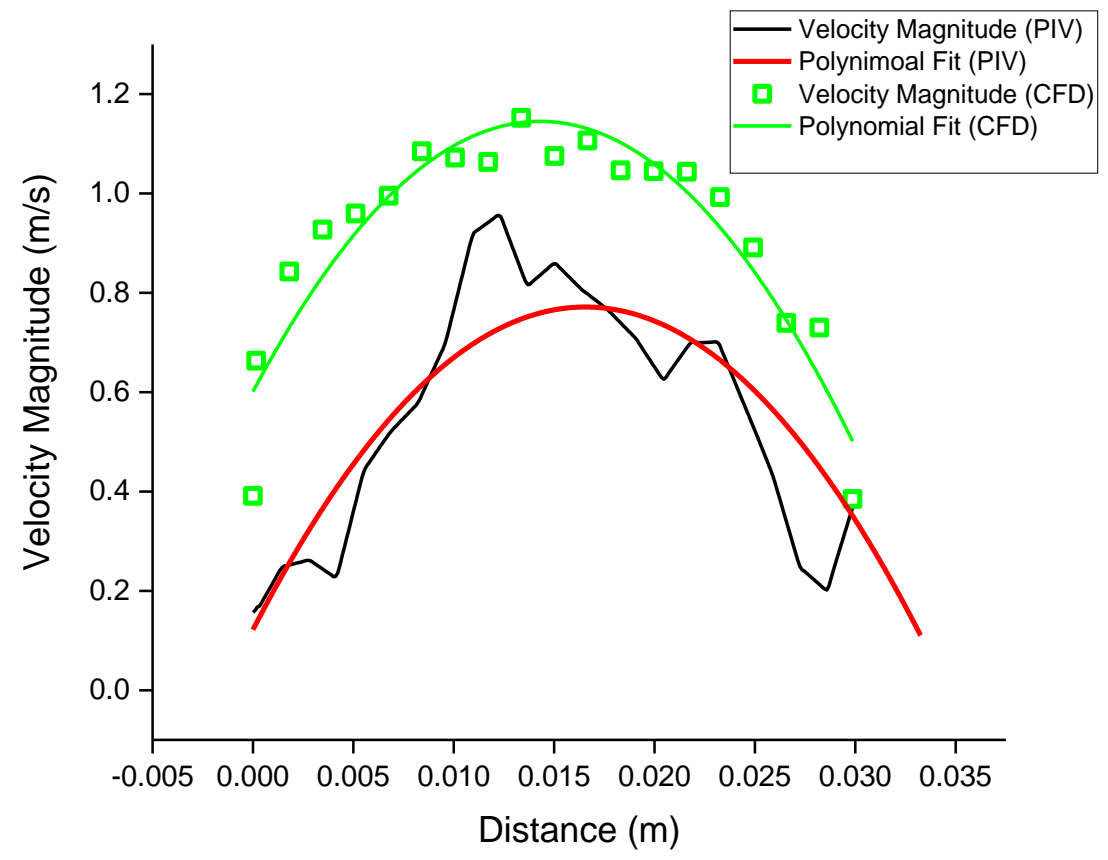

Fig. 5. Velocity magnitude at inlet nozzle

Based on Figure 5, it can be seen that the velocity distribution at the nozzle tip has a similar pattern in PIV and CFD. Following Figure 3 where the starting point was calculated at the bottom wall of the nozzle, the fluid velocity increases until it reaches the peak in the middle of the nozzle, then decreases again until it reaches the top wall of the nozzle (see Figure 5). The decreasing of fluid velocity in the nozzle wall indicates the boundary layer's influence, where in the nozzle wall, the velocity is to zero. In addition, although the velocity profile pattern at the nozzle tip is similar, but quantitatively the velocity value in the area has a difference with the average value of XYZ.

In addition, the distribution of velocity in the area in front of the nozzle was also observed. The following is a picture of the velocity distribution in the area at the blade inlet or stage 1 (see Figure $3(b)$, green line). 
Similar to Figure 5, Figure 6 also shows the speed distribution on stage 1 has a similar pattern although it is quantitatively different. The difference percentage from both methods caused by uneven amount of light from the laser, since, the nozzle area was just too far from the laser light itself. Seeing the losses that have not been defined in those conditions in the crossflow turbine simulation method, so the average velocity value in the computational method results is greater than the experimental method. Lack of cross-correlation between two seeding particles leads to a miscalculation of the experimental velocity value even though the resin and rhodamine $B$ have the potential to reflect the laser light [36] .

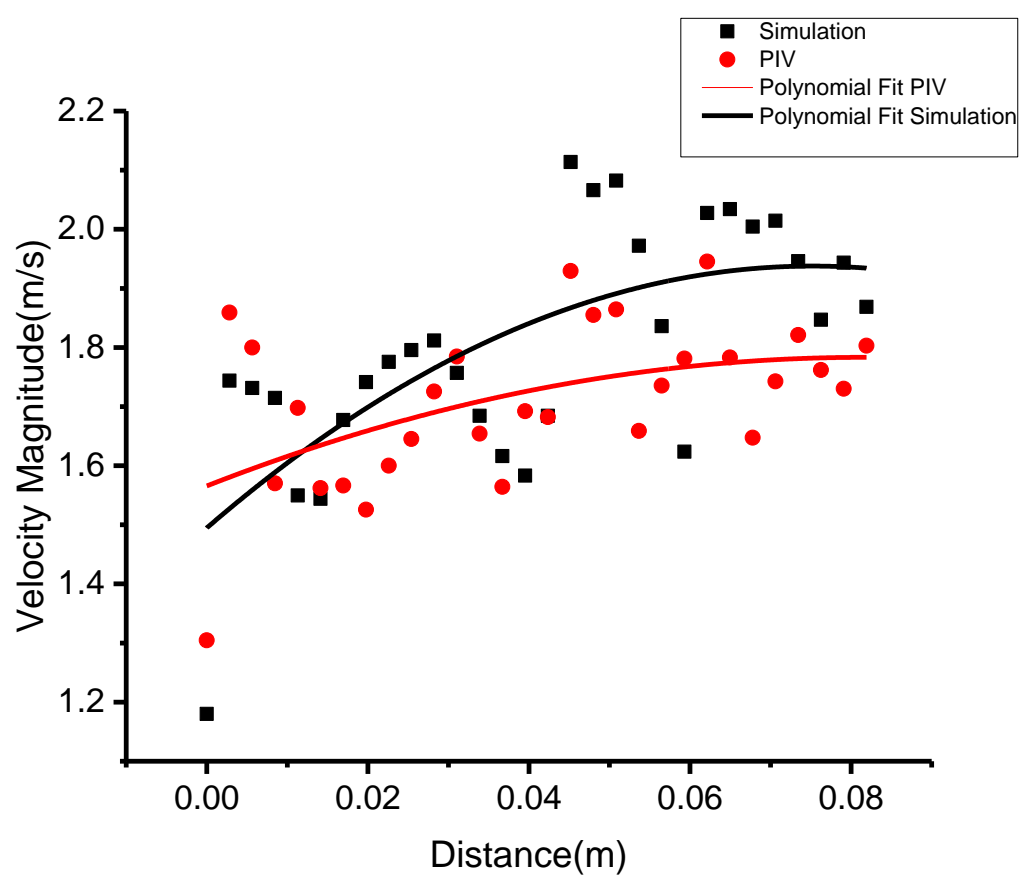

Fig. 6. Velocity distribution at stage 1 crossflow turbine

\subsection{Separation}

Several phenomena can be observed at both methods (PIV and CFD), such as separation in the blade tip, as we see in the blade tip. This phenomenon caused by the fluids that flows around the solid bodies will generate back flow builds turbulence [37]. Furthermore, separation caused by pressure loss because of kinetic energy in the turbulence area which follows the flows cannot be reattached. The Separation phenomenon in the blade is seen in the Figure 7 below.

In Figure 7 both of the phenomenon basically shows similar separation phenomenon in the end of blade tip. Computational method could possibly shows the phenomenon compared to PIV method in this experiment.

Besides its phenomenon in the blade area of cross flow turbines, reflections on the seeding particle depend on the laser emissions and seed material. Seeding particle reflections depends on the types of laser, laser power output and lights sheet thickness. However, the light sheet thickness can be ignored. Besides that, seeding particles property must be followed by the working fluid density and characteristics. So, the particles can move follow the flow of the working fluid. 


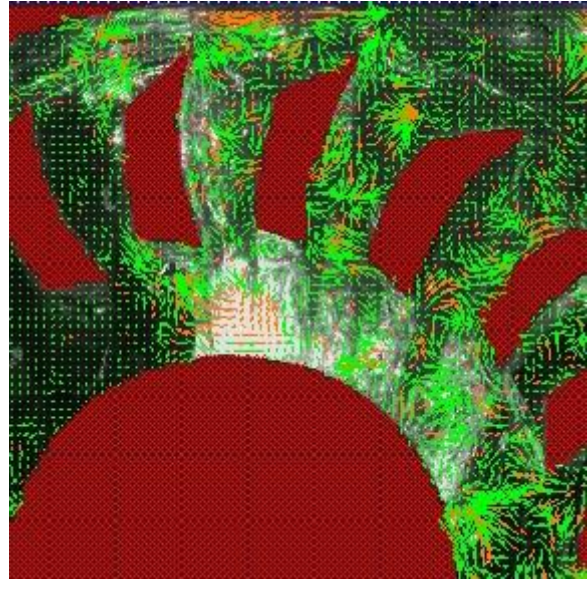

(a)

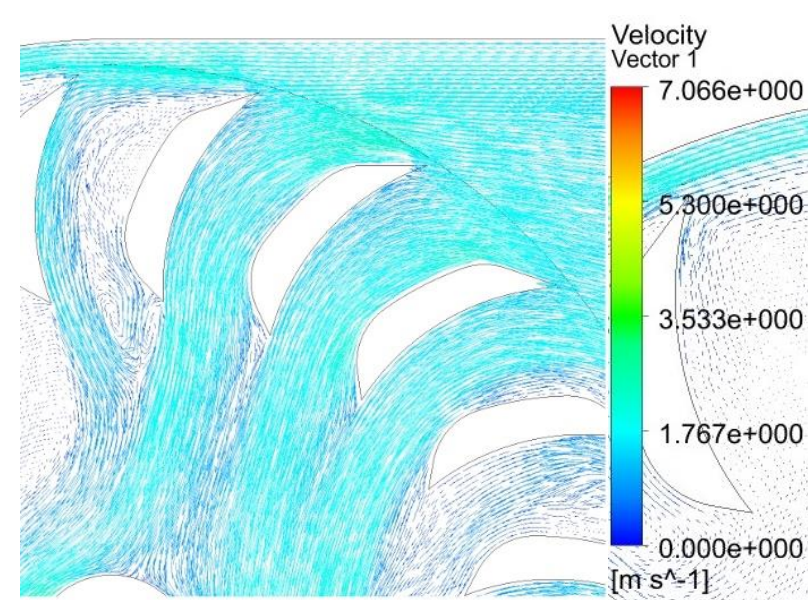

(b)

Fig. 7. Separation phenomeon in blade tip

\section{Conclusions}

This study showed that an inexpensive material resin and rhodamine $B$ as a seeding particle can represent flow inside pico-hydro cross-flow turbine compared to the CFD method. From the results, although an increase in accuracy is still needed in relation to the measurement of flow discharge at the inlet nozzle, several phenomena can be observed at both methods (PIV and CFD), such as separation in the blade tip.

\section{Acknowledgement}

This work was supported by the Ministry of Research, Technology, and Higher Education (KEMENRISTEK DIKTI) of the Republic of Indonesia with grant number NKB2667/UN2.RST/HKP.05.00/2020.

\section{References}

[1] Razak, J. A., Y. Ali, M. Alghoul, Mohammad Said Zainol, Azami Zaharim, and K. Sopian. "Application of crossflow turbine in off-grid pico hydro renewable energy system." Proceeding of the American-Math 10 (2010): 519-526.

[2] Adanta, Dendy, Budiarso Warjito, Aji Putro Prakoso, and Elang Pramudya Wijaya. "Effect of blade depth on the energy conversion process in crossflow turbines." CFD Letters 12, no. 1 (2020): 123-131.

[3] Khattak, M. A., NS Mohd Ali, NH Zainal Abidin, N. S. Azhar, and M. H. Omar. "Common Type of Turbines in Power Plant: A Review." Journal of Advanced Research in Applied Sciences and Engineering Technology 3, no. 1 (2016): 77100.

[4] Siswantara, Ahmad Indra, Aji Putro Prakoso Budiarso, Gun Gun R. Gunadi, and Dendy Warjito. "Assessment of turbulence model for cross-flow pico hydro turbine numerical simulation." CFD Letters 10, no. 2 (2018): 38-48.

[5] Sammartano, Vincenzo, Gabriele Morreale, Marco Sinagra, and Tullio Tucciarelli. "Numerical and experimental investigation of a cross-flow water turbine." Journal of Hydraulic Research 54, no. 3 (2016): $321-331$. https://doi.org/10.1080/00221686.2016.1147500

[6] Slama, Rafika Ben Haj, Bruno Gilles, Maher Ben Chiekh, and Jean-Christophe Béra. "PIV for the characterization of focused field induced acoustic streaming: seeding particle choice evaluation." Ultrasonics 76 (2017): 217-226. https://doi.org/10.1016/i.ultras.2017.01.010

[7] Nishi, Yasuyuki, Tomoyuki Kobori, Nozomi Mori, Terumi Inagaki, and Norio Kikuchi. "Study of the internal flow structure of an ultra-small axial flow hydraulic turbine." Renewable Energy 139 (2019): 1000-1011. https://doi.org/10.1016/i.renene.2019.03.004

[8] Duquesne, Pierre, Yvan Maciel, and Claire Deschênes. "Investigation of flow separation in a diffuser of a bulb turbine." Journal of Fluids Engineering 138, no. 1 (2016). https://doi.org/10.1115/1.4031254

[9] Ciocan, Gabriel Dan, Monica Sanda Iliescu, Thi Cong Vu, Bernd Nennemann, and François Avellan. "Experimental study and numerical simulation of the FLINDT draft tube rotating vortex." (2007): 146-158. 
https://doi.org/10.1115/1.2409332

[10] Pedersen, Nicholas, Poul S. Larsen, and Christian B. Jacobsen. "Flow in a centrifugal pump impeller at design and off-design conditions-part I: particle image velocimetry (PIV) and laser Doppler velocimetry (LDV) measurements." J. Fluids Eng. 125, no. 1 (2003): 61-72. https://doi.org/10.1115/1.1524585

[11] Dupont, P., S. Piponniau, A. Sidorenko, and J. F. Debiève. "Investigation by particle image velocimetry measurements of oblique shock reflection with separation." AIAA journal 46, no. 6 (2008): 1365-1370. https://doi.org/10.2514/1.30154

[12] Melling, A. "Tracer particles and seeding for particle image velocimetry." Measurement science and technology 8 , no. 12 (1997): 1406. https://doi.org/10.1088/0957-0233/8/12/005

[13] Alahyari, Abbas, and Ellen K. Longmire. "Dynamics of experimentally simulated microbursts." AIAA journal 33, no. 11 (1995): 2128-2136. https://doi.org/10.2514/3.12957

[14] Liu, Z-C., C. C. Landreth, R. J. Adrian, and T. J. Hanratty. "High resolution measurement of turbulent structure in a channel with particle image velocimetry." Experiments in fluids 10, no. 6 (1991): 301-312. https://doi.org/10.1007/BF00190246

[15] Westerweel, J., and A. A. Draad. "Measurement of temporal and spatial evolution of transitional pipe flow with PIV." In Developments in Laser Techniques and Fluid Mechanics, pp. 311-324. Springer, Berlin, Heidelberg, 1997.

[16] McCluskey, D. R., T. S. Laursen, J. Juul Rasmussen, and B. Stenum. "Evolution of vortical flow fields measured by real time PIV system." In 1995 ASME/JSME Fluids Engineering and Laser Anemometry Conference and Exhibition, pp. 313-318. American Society of Mechanical Engineers, 1995.

[17] Willert, Christian E., and Morteza Gharib. "Digital particle image velocimetry." Experiments in fluids 10, no. 4 (1991): 181-193. https://doi.org/10.1007/BF00190388

[18] Hart, Douglas P. "Sparse array image correlation." In Developments in Laser Techniques and Fluid Mechanics, pp. 53-74. Springer, Berlin, Heidelberg, 1997. https://doi.org/10.1007/978-3-642-60911-4 5

[19] Roth, G., D. Hart, and J. Katz. "Feasibility of using the L64720 video motion estimation processor (MEP) to increase efficiency of velocity map generation for particle image velocimetry (PIV)." Laser Anemometry (1995): 387-93. https://doi.org/10.1007/BF00209510

[20] Khoo, B. C., T. C. Chew, P. S. Heng, and H. K. Kong. "Turbulence characterisation of a confined jet using PIV." Experiments in fluids 13, no. 5 (1992): 350-356.

[21] Zhang, Jingyi, Bo Tao, and Joseph Katz. "Three Dimensional Velocity Measurements Using Hybrid HPIV." In Developments in Laser Techniques and Fluid Mechanics, pp. 275-287. Springer, Berlin, Heidelberg, 1997. https://doi.org/10.1007/978-3-642-60911-4_17

[22] Hassan, Y. A., R. S. Martinez, O. G. Philip, and W. D. Schmidl. "Flow measurement of a two-phase fluid around a cylinder in a channel using particle image velocimetry." Transactions of the American Nuclear Society 71, no. CONF941102- (1994).

[23] Smith, G. H., I. Grant, A. Liu, D. Infield, and T. Eich. A wind tunnel examination of vortices shed from a wind generator using particle image velocimetry. HERIOT-WATT UNIV EDINBURGH (UNITED KINGDOM), 1992.

[24] Grant, I., and X. Wang. "Directionally-unambiguous, digital particle image velocimetry studies using a image intensifier camera." Experiments in fluids 18, no. 5 (1995): 358-362. https://doi.org/10.1007/BF00211392

[25] Magness, C., O. Robinson, and D. Rockwell. "Laser-scanning particle image velocimetry applied to a delta wing in transient maneuver." Experiments in fluids 15, no. 3 (1993): 159-167. https://doi.org/10.1007/BF00189882

[26] Johari, H., D. Dabiri, A. Weigand, and M. Gharib. "On the relationship between the formation number and passive scalar pinch-off in starting jets." In Developments in Laser Techniques and Fluid Mechanics, pp. 399-410. Springer, Berlin, Heidelberg, 1997. https://doi.org/10.1007/978-3-642-60911-4 25

[27] Graham, Lachlan JW, and Julio Soria. "A study of an inclined cylinder wake using digital particle image velocimetry." (1994).

[28] Dieter, Jochen, Roland Bremeyer, Frank Hering, and Bernd Jähne. "Flow measurements close to the free air/sea interface." In Proc. 7th Int. Symp. on Applications of Laser Techniques to Fluid Mechanics, Lisbon. 1994.

[29] Novotný, J., and L. Manoch. "The criterion of choosing the proper seeding particles." Engineering Mechanics (2012): 201.

[30] Adanta, Dendy, Richiditya Hindami, and Ahmad Indra Siswantara. "Blade depth investigation on cross-flow turbine by numerical method." In 2018 4th International Conference on Science and Technology (ICST), pp. 1-6. IEEE, 2018. https://doi.org/10.1109/ICSTC.2018.8528291

[31] Kevin, Celine, Dendy Adanta, and Aji Putro Prakoso. "Computational methods for predicting a pico-hydro crossflow turbine performance." CFD Letters 11, no. 12 (2019): 13-20.

[32] Roache, Patrick J. "Quantification of uncertainty in computational fluid dynamics." Annual review of fluid Mechanics 29, no. 1 (1997): 123-160. https://doi.org/10.1146/annurev.fluid.29.1.123

[33] Pedocchi, Francisco, J. Ezequiel Martin, and Marcelo H. García. "Inexpensive fluorescent particles for large-scale 
experiments using particle image velocimetry." Experiments in Fluids 45, no. 1 (2008): 183-186. https://doi.org/10.1007/s00348-008-0516-2

[34] Chen, Fang, Hong Liu, Zifeng Yang, and Hui Hu. "Tracking characteristics of tracer particles for PIV measurements in supersonic flows." Chinese Journal of Aeronautics 30, no. 2 (2017): 577-585. https://doi.org/10.1016/j.cja.2016.12.033

[35] Sciacchitano, Andrea, and Bernhard Wieneke. "PIV uncertainty propagation." Measurement Science and Technology 27, no. 8 (2016): 084006. https://doi.org/10.1088/0957-0233/27/8/084006

[36] Nobach, Holger, and Eberhard Bodenschatz. "Limitations of accuracy in PIV due to individual variations of particle image intensities." Experiments in fluids 47, no. 1 (2009): 27-38. https://doi.org/10.1007/s00348-009-0627-4

[37] Kreith, Frank, and Raj M. Manglik. Principles of heat transfer. Cengage learning, 2016. 